\title{
First Language Bidialectism and Associative Learning in Second
}

\section{Language Acquisition}

\author{
Weifeng $\operatorname{Han}^{1 *}$ \\ ${ }^{1}$ Department of Speech Pathology and Audiology, Flinders University, Adelaide, SA, Australia \\ *Weifeng Han, E-mail: han0174@flinders.edu.au
}

\begin{abstract}
The faculty of grammar has long been known to be critical to language acquisition, but recent studies have called into question whether innate capacities included only knowledge of grammatical structure. This paper reports research on language-learning impaired children's language acquisition and first language (L1) bidialectal children learning a second language. It proposes that learners will benefit from their L1 bidialectal knowledge in second language (L2) learning, since L1 bidialectals exhibit better syntactic awareness of L2 specific structures. It further argues that mechanism of association, rather than rule computation, plays a more important role in L2 acquisition.
\end{abstract}

\section{Keywords}

bidialectism, second language acquisition, associative learning

\section{Introduction}

Multilingualism will be enhanced in the future since there will not be a language that dominates the world (Graddol, 2004). This is why second language learning, or acquisition, is becoming a more and more intriguing topic today. One thing, among others, that stands in the way of successful second language acquisition is that there are negative transfers of learner's first language (L1) on the second language's (L2) syntax, while the bigger the syntactic differences between L1 and L2 are, the more negative transfers there will be (Nitschke, Kidd, \& Serratrice, 2010; Whitley, 2002).

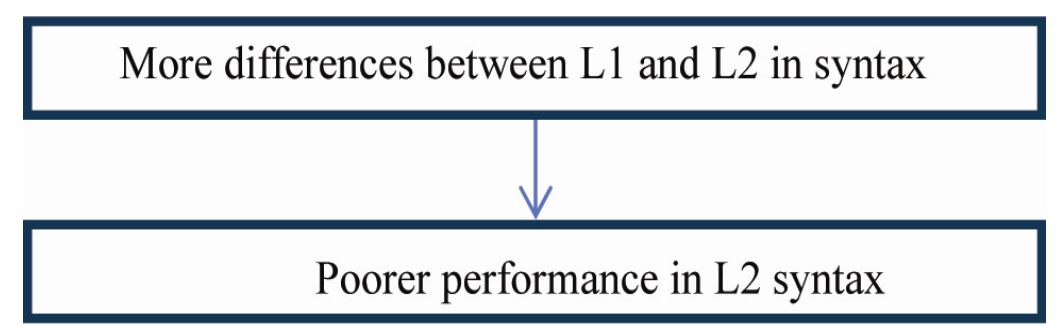

Figure 1. L1 Transfer Disadvantage

Therefore, it seems obvious that, regardless of the enormous individual variation in L2 learning (Sakai, 2005), a Japanese German learner would experience more negative transfer than a Dutch native 
learning German, since the latter would be more familiar with either the rule computation or lexical association in the target language (Kolata, 1987). So would a Chinese English learner comparing to a French native learning English. (Note 1)

To most historical linguists, Chinese is more like a language family that consists of a large number of dialects, most of which have co-existed since before the Qin dynasty (221-206 B.C.). The dialectal complexity is in many ways analogous to the Romance language family. For example, there is as much difference between Pekingese and the Chaozhou dialect as there is between Italian and French; or the Hainan Min dialect are as different from the Xiang dialect as Spanish is from Romanian (Norman, 1988, p. 187). Though politically or socially speaking there are differences between the standard and non-standard among Chinese dialects, linguistically, and clinically, they are equally important.

\section{L1 Bidialectal Transfer Benefit}

In first language acquisition studies, the mechanisms that prevent learners from producing wrong sentences (such as 4 or 5 below; asterisks indicate ungrammaticality) by analogy to normal sentences (such as 1 and 2) have been a source of mystery (Seidenberg, 1997, p. 1602).

(1) I loaded the bricks onto the truck.

(2) I loaded the truck with bricks.

(3) I poured the water onto the ground.

(4) *I poured the ground with water.

(5) *I filled the bricks onto the truck.

(6) I filled the truck with bricks.

Such an ability to make right generalizations of verbs for first language learners are not based on simple erratic inputs, since no one tells them explicitly which sentence is wrong. This is also true to L2 learners, because teachers and textbooks do not (and cannot) offer a complete list of wrong sentences. However, L2 learners may encounter more difficulties in the same structures due to their L1 interference. For example, with verbs of the same meaning, acceptability of the Chinese sentences (corresponding to the English 1 to 6) are different (AUX and PREP refers to auxiliary and preposition):

(7) 我 把 砖块 装到卡车上。

I AUX brick load PREP truck PREP

I loaded the bricks onto the truck.

(8) 我把卡车装上砖块。

I AUX truck load PREP brick

I loaded the truck with bricks.

(9) 我把水倒在地上。

I AUX water pour PREP ground PREP

I poured the water onto the ground.

(10) 我把地倒上水。 
I AUX ground pour PREP water

I poured the ground with water.

\section{(11) *我 把 砖块 填 到 卡车上。 \\ I AUX brick fill PREP truck PREP}

I filled the bricks onto the truck.

$(12) *$ 我 把 卡车 填 上 砖块。

I AUX truck fill PREP brick

I filled the truck with bricks.

20 adult English learners (10 speak Mandarin as L1, 10 Shanghainese (Note 2)) were observed for their judgement of sentences 1 to 6 . The results show that most subjects accept sentences 1 to 3 and reject 5 as English natives would do, but only around half reject 4 or accept 6 (Figure 2). The "wrong intuition" of 4 and 6 can be obviously attributed to the negative transfer from the subjects' existing knowledge of Chinese.

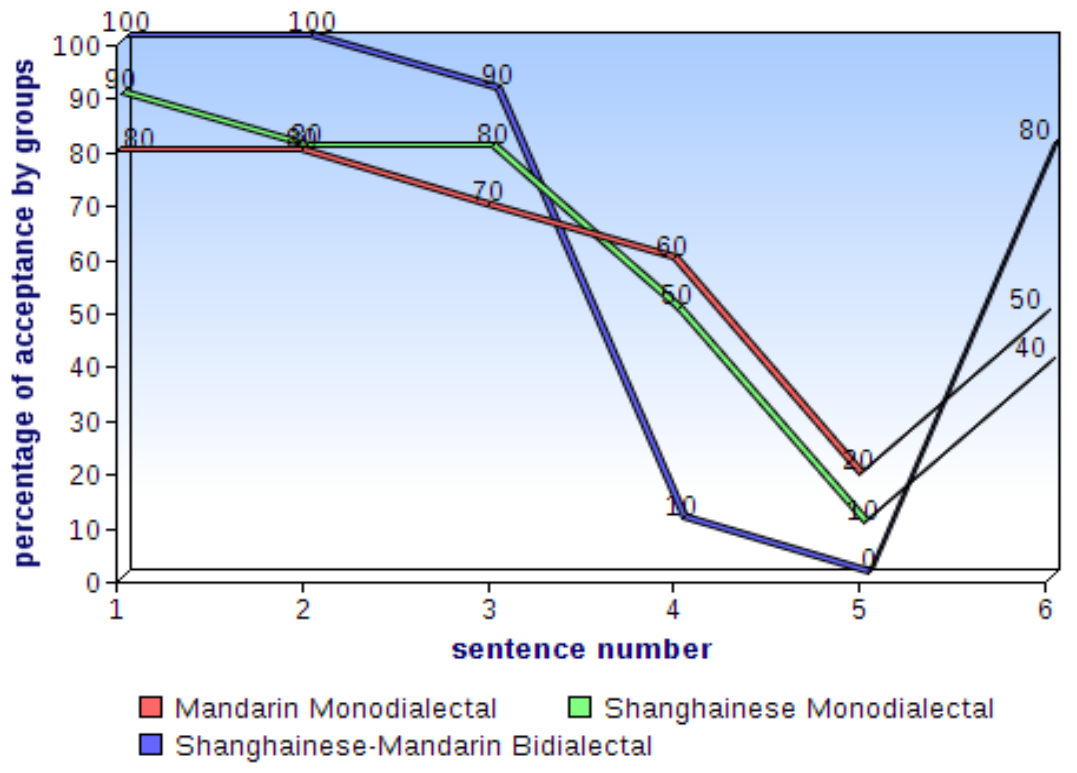

Figure 2. L2 Sentence Acceptability Test by Mandarin Monodialectals, Shanghainese Monodialectals and Shanghainese-Mandarin Bidialectals

The above 20 subjects, however, are Mandarin and Shanghainese monodialectals, i.e. the 10 subjects in the first group speak only Mandarin as their L1 and those in the second group only Shanghainese (Note $3)$. Here is what interesting comes: a third group of 10 Shanghainese-Mandarin bidialectals were asked to do the same test, but with significant differences in the results from those of the other two monodialectal groups, that is most subjects reject sentences 4 and 5 while accept the rest (Figure 2).

It is believed that, based on previous linguistic experience, a variety of probabilistic constraints are 
exploited by language learners to resolve ambiguities (MacDonald, Pearlmutter, \& Seidenberg, 1994; Tanenhaus \& Trueswell, 1995). As for bilinguals, even at the age of as early as 12 months, they appear to be more flexible learners of speech structures than monolinguals. Besides, bilinguals are able to learn two different regularities simultaneously while monolinguals can only learn one at a time (Kovács \& Mehler, 2009). The above results, however, suggest that L1 bidialectals are more sensitive to L2 specific structures than monodialectals.

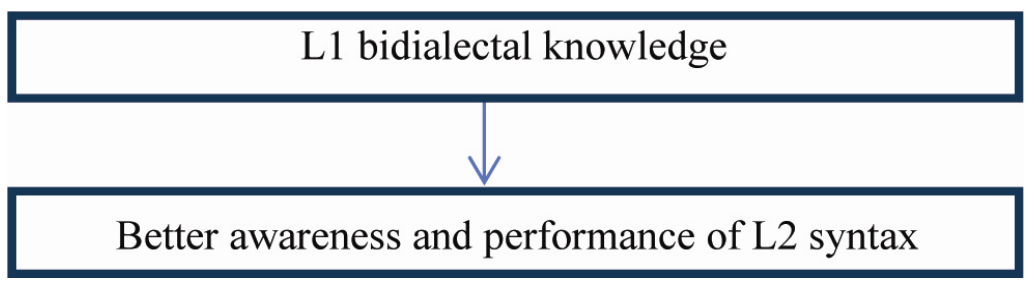

Figure 3. L1 Bidialectal Transfer Benefit

\section{L1 Bidialectals Learn L2 through Association}

As to what constitutes the basis of knowledge, while R. Descartes argued for rules, D. Hume favored associations. It, however, seems to evade the question (i.e. whether learning is based on rules or associations) to say that the truth lies somewhere in the middle (Kolata, 1987). I do not try to provide the truth here. However, I do agree that there's no inconsistency between symbolic computation (i.e. the representationalists' view that mind is essentially a symbol-processing device) and probabilistic computation (i.e. associationists' view that all behavior is driven by probabilities of distributed neural activity) (Lidz \& Pearl, 2007), and both styles of computation can co-exist in the same organism (Yang, 2006). The question is which mechanism plays a more essential role, specifically in second language acquisition?

Saffran et al.'s research (Saffran, Aslin, \& Newport, 1996) found out that infants have access to a powerful mechanism for the computation of statistical properties of the language input. It reveals that language learners may rely on a combination of experience-independent (GRAMMAR) and experience-dependent mechanisms, both of which are involved in the extraction of input. They further argued that infants possess experience-dependent mechanisms that are powerful enough to support the acquisition of any aspect of language. In other words, experience plays a more important role in language acquisition than any other theories suggest.

American children with reading problems can be easily taught to read English represented by Chinese characters with only 2.5 to 5.5 hours of tutoring (Chee, Caplan, \& Soon, 1999). Such an amazing fact reveals that speeches are rather successfully accessed and mapped at the level of words, and experience of characters makes helpful associations. The test results presented in Figure 2 suggest that while rule computation may remain a basic mechanism, bidialectals exhibit stronger associative capacity than monodialectals. Besides, the "deviant" English structures (i.e. 4 and 6 as compared to 10 and 12) are 
indeed irregular forms to Chinese eyes. If we agree that processing of "irregular" forms blocks existing "regular" rules (Pinker, 1991), then the successful processing of such sentences in L2 of the bidialectal group exactly proves that second language acquisition relies more on association than simple rule computation.

\section{Evidence from Language-Learning Impaired Children}

It is true that infants can already represent, extract, and generalize abstract algebraic rules (Falk \& Bardel, 2010). Language-learning impaired children are proved able to improve markedly in their abilities to recognize brief and fast sequences of non-speech and speech stimuli with only 8 to 16 hours training (Crain \& Thornton, 1998). Such a fact strongly indicates that there may not be fundamental defect in the learning machinery, because these children can so rapidly learn the same skills at which they have been defined to be deficient. In other words, rule, which is a more basic mechanism, is separated from association. Further studies also found that language comprehension in language-learning impaired children is improved with acoustically modified speech (i.e. unnatural, synthetic but more rule-prominent speech) (Chung \& Ho, 2010), which precisely tells that it is not the rule that is impaired.

On the other hand, patients with William syndrome are described as hyperlinguistic with grammatical abilities very close to normal people (Bellugi, Bihrle, Jernigan, Trauner, \& Doherty, 1990). The fact that those patients had their Intelligent Quotient measured at around 50 proves, again, that rule is a more basic mechanism. It seems to favour the theory that it is one of several kinds of dissociation in which language is preserved despite severe cognitive impairments, and it suggests that the language system is autonomous of many other kinds of cognitive processing (Pinker, 1991). This, however, only proves that rules are preserved for patients with William syndrome. It does not necessarily prove that the faculty of GRAMMAR is autonomous, unless research with patients without William syndrome but an IQ at or below 50 shows the same results. On the contrary, research involves 3 Shanghainese-Mandarin adolescents (aged 13 to 16) with William syndrome found, however, these children perform much poorer in judgement of L2 (English) specific structures (Han, 2008) (Note 4). This and the above research of language-learning impaired learners all suggest that what stops these patients from successful learning of the target language comes from the impairment of the associative mechanism, not from the impairment of the rule. Evidently, however, L2 acquisition relies more on the development of the mechanism of association, and L1 bidialectals possess a more powerful one.

\section{Conclusion}

If there are innate capacities in language acquisition, these capacities are rather cognitively general that may take the form of biases than a priori knowledge of grammar (Elman et al., 1996; Newport, 1990). In other words, there might be innate capacities that constrain language learning. However, it is questionable that such innate capacities involve GRAMMAR (Seidenberg, 1997). I have proposed that, 
as far as second language acquisition is concerned, the mechanism of rule computation indeed plays a minor role. L1 bidialectals may benefit from their stronger associative memories in L2 learning. This would appear to provide a theoretical basis for not only reconsideration of learners L1 dialectal knowledge in L2 teaching, but, more importantly, also for assessment and treatment of learners with language-learning impairments.

\section{References}

Bellugi, U., Bihrle, A., Jernigan, T., Trauner, D., \& Doherty, S. (1990). Neuropsychological, neurological, and neuroanatomical profile of Williams syndrome. American Journal of Medical Genetics, 6, 115-125.

Chee, M. W., Caplan, D., \& Soon, C. S. (1999). Processing of visually presented sentences in Mandarin and English studied with fMRI. Neuron, 23(1), 127-137.

Chung, K., \& Ho, C. (2010). Second language learning difficulties in chinese children with dyslexia: What are the reading-related cognitive skills that contribute to english and chinese word reading? Journal of Learning Disabilities, 43(3), 195-211.

Crain, S., \& Thornton, R. (1998). Investigations in universal grammar: A guide to research on the acquisition of syntax and semantics. Cambridge, MA: MIT Press.

Elman, J. L., Bates, E. A., Johnson, M. H., Karmiloff-Smith, A., Parisi, D., \& Plunkett, K. (1996). Rethinking Innateness: A connectionist perspective on development. Cambridge, MA: MIT Press.

Falk, Y., \& Bardel, C. (2010). The Study of the Role of the Background Languages in Third Language Acquisition. The State of the Art. International Review of Applied Linguistics in Language Teaching (IRAL), 2, 185-219.

Fasold, R. W. (2006). The politics of language. In R. W. Fasold, \& J. Connor-Linton (Eds.), An Introduction to Language and Linguistics (pp. 371-400). Cambridge: Cambridge University Press.

Graddol, D. (2004). The future of language. Science, 303(5662), 1329-1331.

Han, W. (2008). Object Preposed Sentences and Subject Prominence. Paper presented at the 1st International Workshop on Cognitive Linguistics and Rhetoric, Shanghai.

Han, W., Brebner, C., \& McAllister, S. (in progress). Redefining "Chinese" L1 in SLP-Considerations for the assessment of Chinese bilingual-bidialectal language skills. International Journal of Speech-Language Pathology.

Han, W., \& Shi, D. (2014). The Evolution of fir23kã34 "he says" in Shanghainese. Language and Linguistics, 15(4), 479-494.

Han, W., \& Shi, D. (in press). Topic and Left Periphery in Shanghainese. Journal of Chinese Linguistics.

Kolata, G. (1987). Associations or Rules in Learning Language? Science, 237, 133-134.

Kovács, Á. M., \& Mehler, J. (2009). Flexible Learning of Multiple Speech Structures in Bilingual Infants. Science, 325,611 . 
Lidz, J., \& Pearl, L. (2007). Language Learning Through Selection. Science, 315, 332.

MacDonald, M. C., Pearlmutter, N. J., \& Seidenberg, M. S. (1994). The lexical nature of syntactic ambiguity resolution. Psychological Review, 101(4), 676-703.

Newport, E. L. (1990). Maturational constraints on language learning. Cognitive Science, 14, 11-28.

Nitschke, S., Kidd, E., \& Serratrice, L. (2010). First language transfer and long-term structural priming in comprehension. Language and Cognitive Processes, 25(1), 94-114.

Pinker, S. (1991). Rules of Language. Science, 253, 530-535.

Saffran, J. R., Aslin, R. N., \& Newport, E. L. (1996). Statistical Learning by 8-Month-Old Infants. Science, 274, 1926-1928.

Sakai, K. L. (2005). Language acquisition and brain development. Science, 310(5749), 815-819.

Seidenberg, M. S. (1997). Language Acquisition and Use: Learning and Applying Probabilistic Constraints. Science, 275, 1599.

Tanenhaus, M. K., \& Trueswell, J. C. (1995). Sentence Comprehension. In J. L. Miller, \& P. Eimas (Eds.), Speech Language and Communication (pp. 217-262). San Diego, CA: Adademic Press.

Whitley, M. S. (2002). Spanish/English contrasts: A course in Spanish linguistics (2nd ed.). Washington: Georgetown University Press.

Yang, C. D. (2006). The Infinite Gift: How Children Learn and Unlearn the Languages of the World. New York: Scribner.

\section{Notes}

Note 1. Readers may wish to refer to Paradis et al. (2000) for more details regarding characteristics in the process of learning French as a second language.

Note 2. While it seems to be commonly accepted that Mandarin and Cantonese are two distinct Chinese languages they, and other dialects of Chinese, are treated as dialects in modern linguistic research despite their typological differences. By definition, a dialect is "a regional or social variety of a language characterized by its own phonological, syntactic, and lexical properties" and therefore can be typologically quite distinct (O'Grady, Archibald, Aronoff, \& Rees-Miller, 2001). A language is typically the standard variety, i.e. an official dialect, that is selected through "arbitrary standards" and promoted by the authorities (Fasold, 2006). There are no absolute answers to the question of what constitutes a language and what constitutes a dialect. The fact is the differences among Chinese dialects can be quite considerable. This paper follows the modern Chinese linguistic convention (e.g. Han, Arppe, \& Newman, 2013) and refers to Mandarin, Cantonese and other Chinese varieties as "dialects". Note 3. See Han and Shi $(2014,2015)$ for the typological differences between Mandarin and Shanghainese. Also see Han, Brebner and McAllister (in progress) for a further clarification between the general term of "Chinese" and Mandarin.

Note 4. Three Shanghainese-Mandarin adolescents with William syndrome and 10 normal Shanghainese-Mandarin speakers were presented a list of English sentences with SOV word order that 
is not correct in English but well acceptable in both Mandarin and Shanghainese, such as "I apple eat." or "We papa love." and were asked if these sentences felt right. Both groups have only very basic knowledge of English. However, while the normal group felt confused with most sentences, such as they would ask who loves whom in "We papa love.", none of the three subjects with William syndrome reported any problems with the list. 